\title{
Análise do Processo de Turistificação de Fernando de Noronha (PE) entre os Anos de 1960 e 2016
}

\author{
Itamar José Dias e Cordeiro \\ Nathália Körössy Leite ${ }^{\mathrm{b}}$ \\ Edvânia Tôrres Aguiar Gomesc
}

\section{Resumo}

O turismo é uma invenção humana repleta de propósitos e ideologias. Por isso mesmo, o espaço turístico não deve ser assumido enquanto algo natural. Pelo contrário, deve ser questionado em sua essência, de modo a identificar as intenções por trás de sua produção. Este estudo analisa o processo de turistificação de Fernando de Noronha (um dos destinos mais conhecidos e desejados do país) entre os anos de 1960 e 2017. Metodologicamente, este estudo se caracteriza como uma pesquisa descritiva, de natureza qualitativa, realizada a partir de pesquisas bibliográficas e documentais e entrevistas. A análise do processo de turistificação de Fernando de Noronha identificou que, ao longo da sua história e independentemente da gestão que esteve à frente do arquipélago, o espaço insular sempre foi pensado para cumprir o papel de um destino de luxo. Essa tendência, aliás, permanece até os dias de hoje. Constatou-se que essa lógica tem sido responsável pela migração de diversos ilhéus e pela desestruturação do tecido social local.

Palavras-chave: Turismo; Turistificação; Fernando de Noronha.

\section{Abstract}

Analysis of the Touristification of Fernando de Noronha (PE) between 1960 and 2016

Tourism is a human invention full of purposes and ideologies. For this reason, the tourist space should not be assumed as a natural one. On the contrary, it must be questioned in its essence, in order to identify the intentions behind its production. This paper aimed to analyze the touristification process of Fernando de Noronha (one of the most popular and desired destinations in the country) between 1960 and 2016. Methodologically, this study is characterized as a descriptive research of a qualitative approach, based on bibliographical and documentary research and interviews. The analysis of Fernando de Noronha's touristification process has identified that throughout its history, and regardless of the management that was at the forefront of the archipelago, the island space has always been thought to fulfill the role of a luxury destination. This tendency, moreover, remains nowadays. Is was observed that this logic has been responsible for the migration of several islanders and for the destructuring of the local social fabric.

Keywords: Tourism; Touristification; Fernando de Noranha.

a. Doutor pela Universidade Federal de Pernambuco (UFPE). Docente do curso de Turismo da UFPE, Recife, Pernambuco, Brasil. E-mail: itamar_cordeiro@yahoo.com.br

b. Doutora pela Universidade Federal de Pernambuco (UFPE). Docente do curso de Turismo da UFPE, Recife, Pernambuco, Brasil. E-mail: nathaliakorossy@gmail.com

c. Pesquisadora de pós-doutorado em Geografia pela Universitat Leipzig, Leipzig, Alemanha. Docente do curso de Geografia da Universidade Federal de Pernambuco (UFPE), Recife, Pernambuco, Brasil. E-mail: torres@ufpe.br 


\section{Resumen}

\section{Análisis del Proceso de Turistificación en Fernando de Noronha (PE) entre los años 1960 y 2016}

El turismo es una invención humana repleta de propósitos e ideologías. Por ello, el espacio turístico no debe ser asumido como algo natural. Por el contrario, debe ser cuestionado en su esencia, para identificar las intenciones detrás de su producción. El presente estudio buscó analizar el proceso de turistificación de Fernando de Noronha (uno de los destinos más conocidos y deseados del país) entre los años 1960 y 2016. Metodológicamente, este estudio se caracteriza como una investigación descriptiva, de naturaleza cualitativa, realizada a partir de investigaciones bibliográficas y documentales, y entrevistas. El análisis del proceso de turistificación de Fernando de Noronha identificó que, a lo largo de su historia e independientemente de la gestión que estuvo al frente del archipiélago, el espacio insular siempre ha sido pensado para cumplir el papel de un destino de lujo. Esta tendencia permanece hasta los días de hoy. Lo que se constató fue que esa lógica ha sido responsable de la migración de diversos isleños y de la desestructuración del tejido social local.

Palabras clave: Turismo; Turistificación; Fernando de Noronha.

\section{INTRODUÇÃO}

Enquanto uma das mais significativas forças econômicas da atualidade, o turismo exerce influência em vários aspectos da sociedade. A turistificação do espaço geográfico é um deles. Conceitualmente a turistificação pode ser entendida como o processo de mudanças no espaço geográfico visando adequá-lo para uma função turística (Barros, 1998). Nesse mesmo sentido Cruz (2007) define turistificação como o processo de apropriação e uso do espaço pelo e para o turismo. Outrossim, Issa \& Dencker (2006) entendem que a turistificação ocorre quando um espaço é apropriado pelo turismo, direcionando suas atividades para o atendimento dos que vêm de fora e alterando a configuração espacial em função de interesses mercadológicos.

É importante estudar tal processo porque ele traz um conjunto de consequências para o território, desde a inserção de novos objetos e refuncionalização de antigos, até a alteração das dinâmicas locais (Almeida, 1999; Coriolano, 2006; Cruz, 2007; Fratucci, 2007; Knafou, 1996; Ouriques, 2005). Através da análise do processo de turistificação, Körössy (2008) descreveu a dinâmica do turismo em Portimão, Portugal; Belhassen, Uriely \& Assor (2007) trataram do tema em Bil'in, Palestina; e Issa \& Dencker (2006) o fizeram em São Luiz do Paraitinga, São Paulo.

Enquanto fenômeno sociocultural e econômico, o turismo tem a capacidade de transformar as dinâmicas locais, seja por meio da dotação de infraestrutura necessária ao desenvolvimento da atividade, seja devido ao aumento dos fluxos de pessoas. Fonseca \& Costa (2004), por exemplo, observam que o crescimento da atividade turística tem provocado a refuncionalização de muitas áreas e o surgimento de novas formas nos destinos turísticos. Já para Loureiro \& Souza (2003), o espectro de atuação da atividade tem repercussões para além do destino turístico em si.

Busca-se com este estudo descrever e analisar o processo de turistificação em Fernando de Noronha, um arquipélago no nordeste do Brasil, cuja economia 
orbita quase exclusivamente em torno do turismo. 0 propósito é descrever como o turismo contribuiu (e ainda contribui) para o processo de produção do espaço insular.

No que toca especificamente ao método de pesquisa, as técnicas empregadas foram: revisão bibliográfica, observação in loco e entrevistas. A revisão bibliográfica consistiu em consulta a livros, periódicos (nacionais e internacionais) e trabalhos acadêmicos sobre Fernando de Noronha. A observação in loco, por sua vez, possibilitou um contato presencial e próximo com o objeto investigado. A observação empregada foi a sistemática e não participante, opção justificada pelo fato de que a interação com a comunidade - sem a exigência de se assumir como "membro" dela - é suficiente para obter as informações (em quantidade e profundidade) necessárias aos propósitos do estudo. Sendo sistemática, ou seja, uma pesquisa que emprega instrumentos para coleta de dados, utilizou-se como recurso a entrevista, cujo propósito foi obter elementos que nem a observação nem a revisão de literatura foram capazes de fornecer sobre o processo de turistificação de Fernando de Noronha. Foram entrevistados pesquisadores e ex-funcionários da Administração do Distrito Estadual de Fernando de Noronha (ADEFN, 2014), funcionários que ainda trabalham na ADEFN, além de ilhéus e ex-gestores.

\section{CONSIDERAÇÕES TEÓRICAS SOBRE O PROCESSO DE TURISTIFICAÇÃO}

Com o aperfeiçoamento dos meios de transporte, a redução da jornada de trabalho e a instituição das férias remuneradas, assistiu-se a partir da segunda metade do século XX a um boom da atividade turística mundial (Krippendorf, 2003). Os 25 milhões de viajantes internacionais registrados em 1950 se transformaram em 763 milhões em 2004. Em 2012, segundo UNWTO (2016), esse número chegou à marca de 1 bilhão e atualmente ultrapassa 1,2 bilhão, com previsões de alcançar 1,4 bilhão de viajantes internacionais em 2020 e 1,8 bilhão em 2030. Estatísticas do turismo mostram uma atividade econômica em expansão, que movimentou em 2015 cerca de 1,2 bilhão de turistas no mundo e gerou US\$ 1,5 trilhão em receitas de exportação (UNWTO, 2016).

Um dos corolários dessa busca pelo preenchimento do tempo livre por meio da prática do turismo foi a multiplicação de territórios planejados e organizados com o fim precípuo de atender aos anseios dos visitantes, oferecendo equipamentos voltados para o lazer (Sousa, 1994; Urry, 1996). Afinal, conforme observa Nicolas (1996), o turismo é uma prática social genuinamente territorial.

A partir do momento em que a atividade turística se desenvolve em dado território, passa a promover a (re)funcionalização desse espaço e a consequente inserção de um novo sistema de objetos condizentes com a nova funcionalidade (Cruz, 2007; Körössy, 2008).

A turistificação é, por assim dizer, um processo de produção do espaço para fins precipuamente turísticos, por meio do qual se instauram no espaço transformações (sociais, culturais, econômicas, políticas, físicas e ambientais), com inserção de novos objetos (meios de hospedagem, equipamentos de lazer, ócio, restauração etc.), apropriação de objetos já existentes, modificação de seus antigos 
significados, ou ainda refuncionalização de áreas, atribuindo novos usos ao espaço e adaptando as estruturas territoriais preexistentes (Almeida, 1999).

Entender a turistificação enquanto um processo de produção do espaço implica em considerar, tal como Lefebvre (2013), que o espaço é organizado, ocupado e transformado para atender aos interesses de determinados agentes. Segundo Almeida (1999), os espaços se turistificam no momento em que são destinados a atender às satisfações dos que chegam de fora.

Considerando que os espaços turísticos refletem os valores da sociedade em que se inserem, pode-se afirmar que a turistificação é fortemente influenciada pelo conjunto de valores e ideologias da sociedade em determinado contexto histórico. Nesse sentido, conforme lembra Lefebvre (1976 apud Soja, 1993, p. 102):

O espaço não é um objeto científico afastado da ideologia e da política; sempre foi político e estratégico. Se o espaço tem uma aparência de neutralidade e indiferença em relação a seus conteúdos e, desse modo, parece ser "puramente formal", a epítome da abstração racional, é precisamente por ter sido ocupado e usado, e por já ter sido o foco de processos passados cujos vestígios nem sempre são evidentes na paisagem. 0 espaço foi formado e moldado a partir de elementos históricos e naturais, mas esse foi um processo político. 0 espaço é político e ideológico.

Dentre esses agentes externos, Knafou (1996) identifica essencialmente três tipos: turistas, mercados e promotores territoriais. Cada um - ou até os três em simultâneo - busca moldar o território a seus anseios e/ou necessidades. 0 que há de singular nessa interpretação é que ela lança luz sobre o fato de que, na produção de um espaço (seja ele turístico, ou não), nada é inocente nem ocasional (Carlos, 2012). Por isso mesmo, evidenciar os agentes e ideologias por trás do processo de produção do espaço é capital para compreendê-lo para além do meramente visível.

Justamente porque atende aos propósitos de agentes específicos (quase sempre externos ao destino), um processo de turistificação geralmente se dá em condições de não sincronia entre o ritmo e o volume da exploração de recursos, por um lado, e a capacidade que o meio oferece de suportar essa exploração, por outro (López, 2002). Tal descompasso leva a uma série de impactos sociais, ambientais e econômicos no destino turístico (Fonteles, 2004; Ouriques, 2005).

Esses impactos, por sua vez, variam consoante o peso do turismo para o local em questão. Em se tratado nomeadamente de pequenos destinos insulares, o turismo tende a ter um peso significativo, devido, entre outras coisas, ao tamanho desses ambientes, à sua população reduzida, à distância em relação ao continente e ao potencial econômico pouco robusto - resultado das restrições de espaço e recursos (Briguglio, 1995; Briguglio \& Briguglio, 1996; Kokkranikal, Mclellan \& Baum, 2003; UNWTO, 2004).

\section{O processo de tUristificação de Fernando de Noronha}

0 arquipélago de Fernando de Noronha (Figura 1) é composto por 21 formações rochosas, entre ilhas, ilhotas e rochedo, que ocupam uma área de aproximadamente $26 \mathrm{~km}^{2}$, dos quais $17 \mathrm{~km}^{2}$ correspondem à ilha principal, única habitada, 
conforme dados do Instituto Brasileiro do Meio Ambiente e dos Recursos Naturais Renováveis (Ibama, 2005), distando 545 km de Recife (PE).

Figura 1 - Arquipélago de Fernando de Noronha

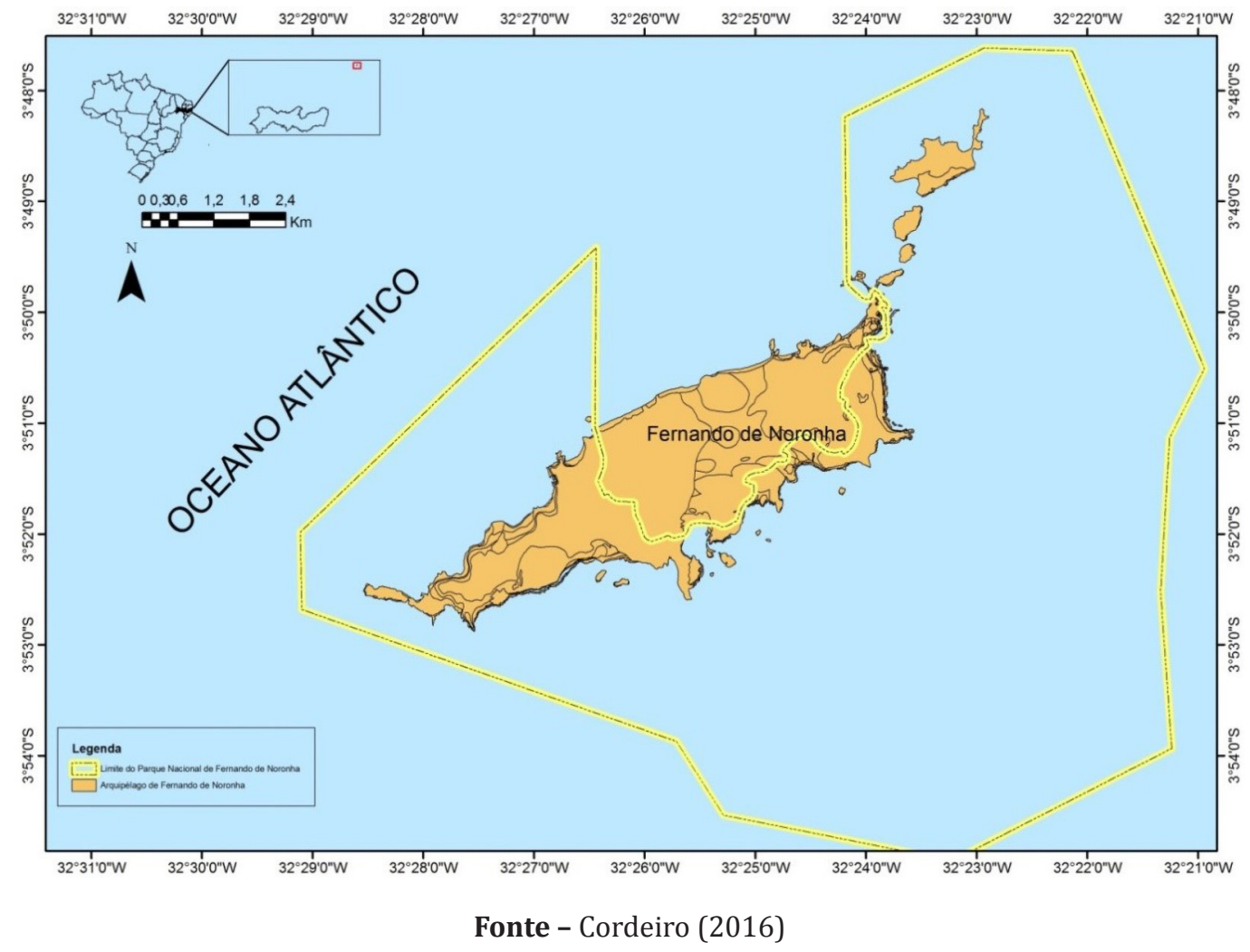

Segundo a versão mais difundida, o arquipélago de Fernando de Noronha teria sido descoberto nos primórdios do século XVI, quando a Segunda Expedição Exploradora (1503-1504), comandada pelo português Gonçalo Coelho, partiu de Lisboa a 10 de maio de 1503 (Lins e Silva, 2013). Um nobre português de ascendência inglesa, chamado Fernão de Loronha, financiara essa expedição e, por isso mesmo, recebeu o arquipélago a título de capitania hereditária, em janeiro de 1505, tornando-se o primeiro donatário em terras do Brasil (Rocha Lima, 2000). Contudo, jamais tomou posse da propriedade. Não havendo providências para sua ocupação, o arquipélago (agora denominado Fernando de Noronha) acabou ocupado por holandeses (1629-1654) e franceses (1736-1737), até ser retomado pelos portugueses em 1737, quando passou a integrar a capitania de Pernambuco (Lins e Silva, 2013).

Expulsos os franceses, a Carta Régia de 26 de maio de 1737 ordenou que a ilha fosse "fortificada e cultivada" com objetivo de defender aquele ponto estratégico da costa brasileira das investidas estrangeiras (Costa, 2009 apud Pessoa, 2014, p. 14). Essa determinação foi efetivada por meio da construção da Vila dos Remédios, da Vila da Quixaba e do sistema fortificado - um conjunto de dez fortificações considerado "o maior sistema defensivo do século XVIII" (Lins e Silva, 2013, p. 150). A partir dessa ocupação portuguesa, o arquipélago passou a servir como "Colônia Correcional para presos comuns (ladrões, assassinos, moedeiros falsos...), gente condenada a longas penas, que era 'exilada' do continente, 
mas constituía 'excelente mão-de-obra' para todos os trabalhos" (Lins e Silva, 2013, p. 37).

Dois séculos depois, em 1938, durante o Estado Novo, a ilha principal é convertida em um presídio político destinado a "concentração e trabalho de indivíduos reputados perigosos à ordem pública, ou suspeitos de atividades extremistas" (BRASIL, 1938). No entanto, por ocasião da Segunda Guerra Mundial o arquipélago foi transformado no Território Federal de Fernando de Noronha (TFFN) e nele se instalou uma base militar, tendo em conta sobretudo as possibilidades de invasão e defesa das rotas marítimas e aéreas do Atlântico que o arquipélago proporcionava por sua localização (Lins e Silva, 2013). No contexto da guerra e sob administração militar, foi autorizada a presença norte-americana na ilha.

Os militares (brasileiros e norte-americanos) ergueram novos núcleos habitacionais, criaram quartéis de grandes proporções, construíram uma usina elétrica e requalificaram antigos prédios coloniais, fazendo deles sedes de serviços e grupamentos (Lins e Silva, 2013). Além disso, edificaram trincheiras de observação, bases de peças bélicas, galpões e um molhe para atracação de embarcações na Baía de Santo Antônio, cujo principal objetivo foi viabilizar o descarrego "das peças para a luta nunca travada, as baterias antiaéreas, as de artilharia de costa, os pesados caminhões e tudo o mais que era necessário" (Lins e Silva, 2013, p. 263). Com o fim da guerra, os militares americanos partiram, os brasileiros permaneceram e a ilha retomou sua função prisional, sob administração do Ministério da Guerra.

Em 1952, dessa vez no contexto da Guerra Fria, os americanos retornaram a Fernando de Noronha. Por meio de um acordo militar entre Brasil e Estados Unidos, o arquipélago foi disponibilizado para a construção de um Posto de Observação de Teleguiados, estrutura que tinha como função acompanhar os experimentos de projéteis teleguiados lançados de Cabo Canaveral, na Flórida (Nascimento, 2009) e fazia parte dos esforços para frear um possível avanço comunista na América Latina. A nova presença norte-americana em Fernando de Noronha, assim como ocorreu durante a Segunda Guerra, desencadeou grandes transformações na paisagem da ilha: estradas foram abertas, o campo de pouso foi aumentado, radares, foguetes e tudo o que havia de mais moderno em matéria de armamento foi ali empregado (Nascimento, 2009). No final do ano de 1959 os norte-americanos deixam o arquipélago porque "as inovações tecnológicas não mais necessitavam do rastreamento feito em terras” (Lins e Silva, 2013, p. 249). É a partir daí que tem início o processo de turistificação de Fernando de Noronha.

\section{Os primórdios do turismo entre as décadas de 1960 e 1970}

Quando os norte-americanos partiram de Fernando de Noronha, deixaram para trás toda a infraestrutura que haviam construído. Em 1965, uma dessas estruturas, o Posto de Observação de Teleguiados, construída no Bairro do Boldró, foi adaptada e transformada na Pousada Esmeralda, dando origem ao primeiro meio de hospedagem de Fernando de Noronha, com 50 apartamentos e 120 leitos (Lins e Silva, 2013).

A partir de 1969, a pedido do então governador do TFFN, Coronel Jayme Augusto da Costa e Silva, ao Ministério do Exército, é autorizada a visitação da 
ilha por civis (Lins e Silva, 2013). Em 1974 a Transbrasil começou a operar a primeira linha regular de voos, com viagens aos sábados e domingos; em 1981 ocorreu uma tentativa de inclusão de Fernando de Noronha em roteiros marítimos, experiência que não obteve êxito por falta de condições operacionais; e em 1982 tentou-se estabelecer uma nova frequência de voos regulares partindo de Natal (Cordeiro \& Gomes, 2016).

Esse período marca o início da turistificação, não só pelo surgimento da primeira infraestrutura de hospedagem (a Pousada Esmeralda), mas também por registrar uma mudança de mentalidade no que toca à finalidade do arquipélago: o espaço deixa de ser pensado unicamente em termos de segurança nacional (seja enquanto presídio, seja enquanto base militar) para acolher outras possibilidades, nomeadamente o turismo. Esse entendimento vai amadurecer ao longo da década de 1970 e encontra efetivos desdobramentos em meados dos anos 1980.

\section{A década de 1980 e a lógica do luxo}

Funcionando de forma incipiente (no que toca ao fluxo de visitantes), precária (em termos de infraestruturas de lazer e hospedagem) e desorganizada (em relação ao ordenamento do espaço para a atividade), o território de Fernando de Noronha passou a ser efetivamente pensado para fins turísticos a partir de 1986, quando, ainda sob a gestão dos militares, alguns órgãos ligados ao turismo foram convidados a avaliar as condições do arquipélago para sustentar fluxos de visitação (Lins e Silva, 2013). Conforme matéria veiculada no Jornal do Commércio de 25 de maio de 1986,

o ministro-chefe do Estado Maior das Forças Armadas (EMFA) almirante José Maria Amaral Oliveira, e o presidente da Embratur, João Dória Jr. anunciaram a assinatura de um convênio para elaboração de um plano-piloto de exploração turística e econômica do Território.

Através do plano - que, segundo as autoridades, buscará preservar as condições ecológicas - o EMFA remodelará e ampliará o aeroporto local (que hoje opera com aviões do tipo 727 e 737 da Boeing) para que tenha condições de receber os grandes jatos e construirá um porto. Também caberá ao órgão preservar a natureza.

Quanto à Embratur, caberá a coordenação da parte turística do plano. A empresa pretende estimular a construção, pela iniciativa privada de três hotéis (hoje existe apenas um).

O Estado Maior das Forças Armadas (EMFA) contratou então os serviços de uma consultoria (a Hidroservice Engenharia de Projetos Ltda) que elaborou, ainda em 1986, o Plano Diretor de Desenvolvimento para o Território de Fernando de Noronha. A proposta da consultoria entendia que a vocação do arquipélago era a de um turismo sofisticado e de grande escala. Sendo assim, para a turistificação do local foram propostas medidas como: ampliação do porto e do aeroporto; construção de cinco hotéis e cinco pousadas, de um aterro para o lixo, de um centro comercial e de uma marina; instalação de campo de golfe, área para criação de cavalos e prática de hipismo; além de ampliação e reformas no sistema viário, das instalações do governo e do sistema habitacional. A expectativa era 
de que essas intervenções levassem a ilha a comportar mais de dez mil pessoas (Ibama, 1990). Note-se, portanto, que o primeiro movimento no sentido de conceber Fernando de Noronha enquanto destino turístico era voltado para um público de alto poder aquisitivo. Isso fica evidente nas infraestruturas pensadas para a localidade.

A proposta, no entanto, não chegou a se concretizar porque em 30 de junho de 1987 o então presidente José Sarney promulgou a lei no 7.608, que transferiu a administração do TFFN da alçada militar para a civil (Ministério do Interior). Essa lei determinava ainda que o território seria administrado por um governador nomeado pelo presidente da República (artigo $4^{\circ}$ ). Sarney resolve então nomear para o cargo seu amigo e então ouvidor-geral da República, Fernando César Mesquita (Lins e Silva, 2013). A partir daí, Fernando de Noronha entra numa nova fase de turistificação.

\section{A transição para o governo civil e a renovação da lógica do luxo}

Na condição de govenador de Fernando de Noronha, Mesquita ignorou o Plano Diretor encomendado pelos militares. No entanto, nem por isso deixou de imaginar o território enquanto um destino de luxo. Ao assumir a gestão do arquipélago, lançou licitação para a construção de um hotel de luxo "totalmente térreo e indispensável para desenvolver a nossa proposta de turismo com limites", segundo o próprio ex-governador (apud Jornal do Brasil de 17 de maio de 1988).

Conforme matéria publicada no Jornal do Brasil de 14 de abril de 1988:

Já foi dado pela Embratur o sinal verde para a construção de um hotel em Fernando de Noronha. 0 hotel terá classificação de quatro estrelas, 100 apartamentos e os interessados poderão construí-lo em quatro anos, assegurando sua exploração por 50 anos. Depois disso, o proprietário será o governo de Fernando de Noronha. 0 edital de concorrência pública sai amanhã. Com esta obra, o governador Fernando César Mesquita transforma seu território naquilo que, anos atrás, se dizia do Brasil. Uma ilha de prosperidade.

De fato, no dia seguinte publicava-se no Jornal do Brasil:

Governo de Fernando de Noronha e Embratur informam:

$$
\text { AVISO DE LICITAÇÃO }
$$

\section{HOTEL 4 ESTRELAS EM FERNANDO DE NORONHA}

A Empresa Brasileira de Turismo - EMBRATUR, empresa pública federal, vinculada ao Ministério da Indústria e do Comércio, com sede na Rua Marize Barros, no․ 13 - Praça da Bandeira - Rio de Janeiro, e o Governo do Território de Fernando de Noronha tornam público aos interessados que no dia 13 de julho de 1988, no seu auditório, serão recebidos os envelopes de habilitação e proposta econômica, objetivando a implantação e operação de um hotel 4 (quatro) estrelas com 100 (cem) unidades habitacionais na Praia da Conceição no Arquipélago de Fernando de Noronha, sob o regime de arrendamento pelo período máximo de 50 (cinqüenta) anos.

A presente Concorrência será regida pelo disposto no Decreto-Lei n․ 2.300 de 21 de novembro de 1986, e suas posteriores alterações. 
Os interessados poderão adquirir ao preço de $\mathrm{Cz} \$ 50.000,00$ (cinqüenta mil cruzados) o edital de inteiro teor, bem como obter maiores informações na Diretoria de Investimentos da Embratur, no 9o andar do endereço supracitado.

Rio de Janeiro, 15 de abril de 1988.

Note-se, pois, que com o término da tutela militar e o início da administração civil na ilha, a mentalidade muda apenas em termos de forma, não de conteúdo. O que se deixou de lado foram as propostas a serem realizadas e não as intervenções propriamente ditas. Destarte, a despeito das divergências entre o governo militar e o governo de Mesquita, a orientação para o desenvolvimento de um turismo de luxo no arquipélago manteve-se.

No entanto, é preciso observar que as pretensões de Fernando Mesquita para o turismo no arquipélago, dada a conjuntura política, não chegaram a se concretizar. Isso porque em 1988, durante a Assembleia Constituinte, é extinto o TFFN, que passa a fazer parte do estado de Pernambuco (Gonçalves, 2009). Com a reanexação,

o governo de Pernambuco resolveu cancelar todas as ações que impliquem em implementar o turismo do arquipélago de Fernando de Noronha, cuja posse readquiriu através da Constituinte Federal. Ontem, o governador em exercício, Carlos Wilson, tomou a primeira providência e solicitou ao presidente da Embratur, Pedro Grossi Júnior, a suspensão de uma concorrência que vinha sendo realizada para a construção de um hotel de quatro estrelas na ilha, um projeto arquitetado pelo ex-governador Fernando César Mesquita. (Jornal do Commércio, 1988)

Quando passa ao controle do estado de Pernambuco, o modelo de turismo de luxo em Fernando de Noronha é abandonado. A verdade é que, enquanto território federal, Fernando de Noronha gozava de acesso ao Fundo de Participação dos Estados e Territórios (viabilizado durante a gestão de Fernando Mesquita e, em grande medida, devido à sua proximidade com Sarney). Esse recurso, no entanto, deixou de existir com a anexação a Pernambuco. Sem acesso ao dinheiro do referido fundo para administrar o novo território - que, segundo Rozowykwiat (2006, p. 212), custava-lhe o "equivalente às despesas que tinha com 32 municípios do interior" -, o governo do estado encontrou na abertura da ilha ao turismo e, sobretudo, na cobrança pelo seu acesso, a solução para incrementar a receita fiscal e dar conta do novo território (Cleto, 2013). Assim surgiu a Taxa de Preservação Ambiental (TPA), um tributo cobrado de todos aqueles que estivessem em visita turística, segundo estabelece a lei estadual no 10.403, de 29 de dezembro de 1989. É a partir daí que efetivamente ganha fôlego a turistificação de Fernando de Noronha.

\section{Da década de 1990 aos dias atuais: o turismo enquanto meio de dinamização econômica local}

Quando passou ao controle de Pernambuco, o governo do estado optou por estimular a visitação ao arquipélago como forma de gerar receita. Ocorre que esse estímulo não veio acompanhado de providências no sentido de impor um controle rígido sobre quem chegava. Sem essa fiscalização, conforme relatou um 
ex-gestor entrevistado, muitos dos que foram para Fernando de Noronha na condição de turistas acabaram por fixar residência na ilha. Desde então o quantitativo de residentes em Fernando de Noronha não tem parado de crescer (Figura 2).

Figura 2 - Evolução populacional de Fernando de Noronha (1970-2010)

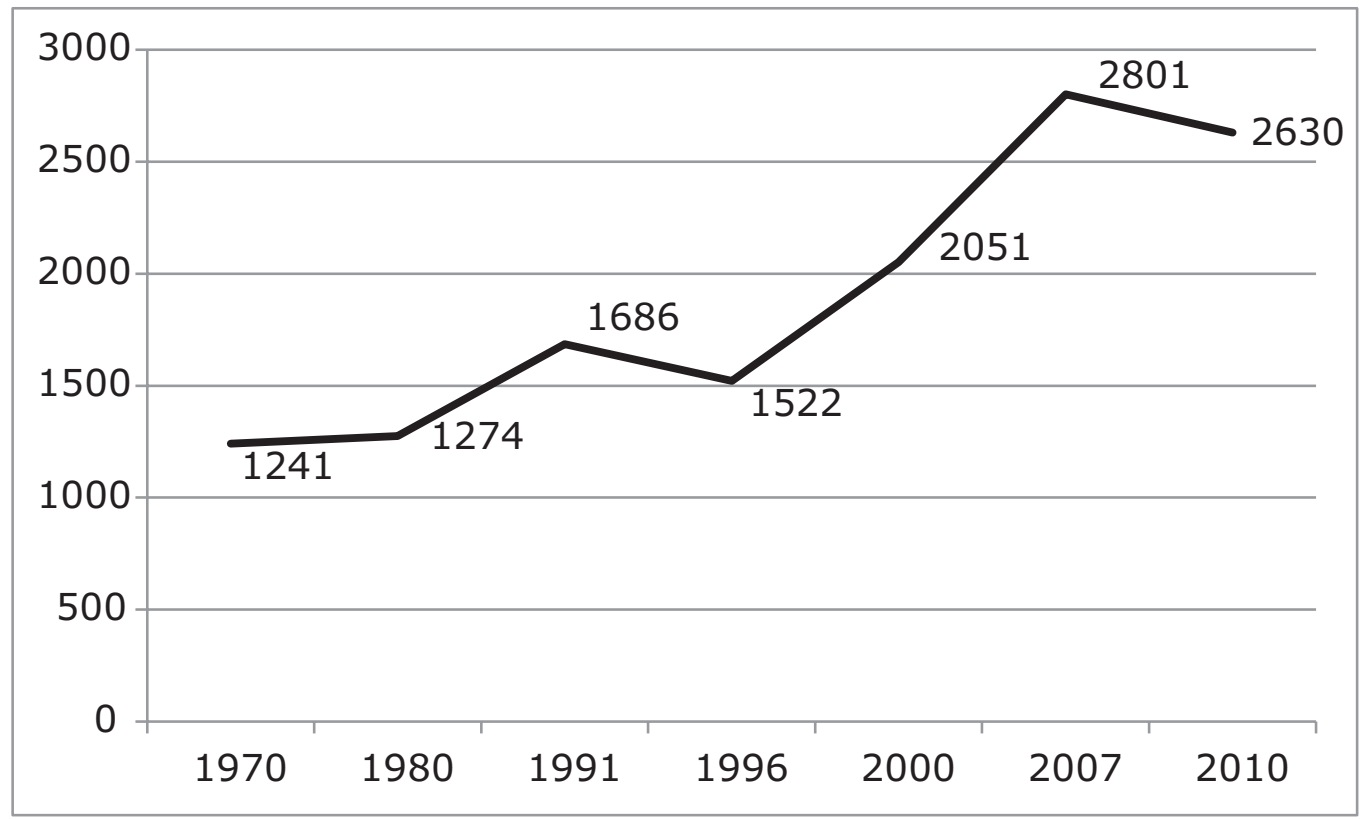

Fonte - Cordeiro (2016)

Os ilhéus (até então sem qualificação, perfil empreendedor ou capital para investir) viram os recém-chegados mais bem instruídos, mais munidos de recursos financeiros e repletos de boas ideias para investir em negócios (como pousadas, barcos ou táxis) tomarem conta de seu território (Ibama, 2005). Em parte, esse predomínio dos forasteiros também se deveu a certa apatia que perdurava entre os ilhéus. Nos primeiros anos após a reanexação ainda havia reticências da comunidade local quanto ao turismo, considerado como algo desnecessário.

Haja vista que até então o Estado custeava tudo, inclusive as necessidades particulares dos ilhéus, a grande maioria destes não estava interessada em prestar qualquer tipo de serviço para os visitantes. Sendo assim, o desejo de trabalhar com turismo era muito mais resultado do acaso, como relata Dona Pituca (apud Mesquita, 2012, p. 51), primeira pessoa a abrir uma pousada no que outrora havia sido a casa paroquial:

Aqui na minha casa eu fiz a primeira pousada de Noronha. Eu trabalhava no hospital, me aposentei muito nova e não queria ficar sem fazer nada. Inventei primeiro de botar almoço. No sábado, feriado e dia de domingo chegava o povo na minha casa: "Hoje nós vamos almoçar por aqui." Eu comecei a fazer almoço, quando vi, minha casa estava cheia. ... Vinham militares, oficiais, tudinho, ficavam por aqui. Eles diziam que já estavam cheios de comer o comê de lá, então no sábado, domingo e feriado vinham para cá. Foi assim que comecei ... e acabei com pousada ....

Outros que se predispuseram a alugar quartos em suas casas foram criticados pela ala mais radical da comunidade. Entretanto, diante da falta de opção 
econômica, não tardou para que estes últimos também começassem a ceder, afinal, sem os recursos federais aos quais estavam acostumados, não havia opção.

Verifica-se, portanto, que o início da turistificação sob a égide do poder estadual é marcado tanto pela falta de planejamento do uso e ocupação do espaço, quanto pelo conflito entre antigos e novos moradores (muitos dos quais pernambucanos que migraram para a ilha incentivados pelo governo estadual). Além disso, nota-se que a turistificação se dá mais por força das circunstâncias do que por um desejo genuíno da comunidade local de se inserir na atividade.

Seja como for, o ato de hospedar turistas, inicialmente visto com desconfiança, acabou por se converter na principal atividade econômica da localidade. 0 resultado disso foi a expansão dos meios de hospedagem, sobretudo de caráter domiciliar: os sete estabelecimentos surgidos na ilha entre 1965 e 1988 (Figura 3) transformaram-se em 34 em 1995 (Figura 4); entre 1996 e 2010 outras 38 novas pousadas são constituídas (Figura 5); e entre 2011 e 2016 surgem mais duas pousadas (Figura 6) ${ }^{1}$.

Importa mencionar que nem todas as pousadas surgidas ao longo dessas décadas foram regulares. Dado que a totalidade do espaço insular está protegida sob a forma de Unidade de Conservação, houve preocupação do poder público em limitar a abertura de novas pousadas. Dessa forma, a administração distrital estipulou um limite de alvarás de funcionamento para pousadas. Entretanto, sendo a implantação de uma pousada a via mais cômoda e certa para o ilhéu extrair renda a partir do turismo crescente em Fernando de Noronha, as disposições legais não foram suficientes para impedir o aparecimento de novas pousadas.

Esses meios de hospedagem que funcionavam sem alvará foram classificados pelo poder público como "pousadas informais", ou seja, estabelecimentos que funcionam como pousadas à revelia da administração distrital. Observe-se que a informalidade não está associada necessariamente à precariedade de instalações e/ou serviços prestados. Por certo há pousadas informais que não funcionam tão bem quanto pousadas formais (regulares). No entanto, o contrário também é verdadeiro: há pousadas informais que possuem instalações e serviços bem mais sofisticados que certas pousadas formais. Formalidade e informalidade estão relacionadas, portanto, à autorização da ADEFN para funcionar como meio de hospedagem.

0 aumento sistemático da oferta de pousadas levou ao respectivo incremento do número de visitantes (Figura 7). Além dos impactos ambientais associados ao acréscimo desse quantitativo de pessoas (Cordeiro, 2016; Cordeiro \& Gomes, 2017), a turistificação implicou também em mudanças expressivas no perfil dos meios de hospedagem.

1. É imprescindível dizer que não se conseguiu acesso aos anos oficiais de abertura das pousadas, uma vez que a ADEFN não os forneceu. Para a periodização aqui apresentada recorreu-se aos dados de ADEFN/DHT (2014), complementados por pesquisa de campo. Assim, diante da ausência de dados oficiais, cumpre advertir que a espacialização aqui descrita, muito embora se aproxime da realidade, não a reflete fidedignamente. 
Figura 3 - Espacialização das pousadas em Fernando de Noronha (1965-1988)

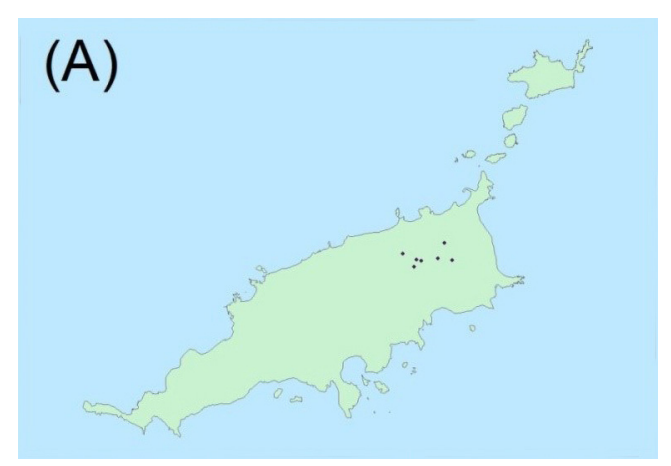

Figura 5 - Espacialização das pousadas em Fernando de Noronha (1996-2010)

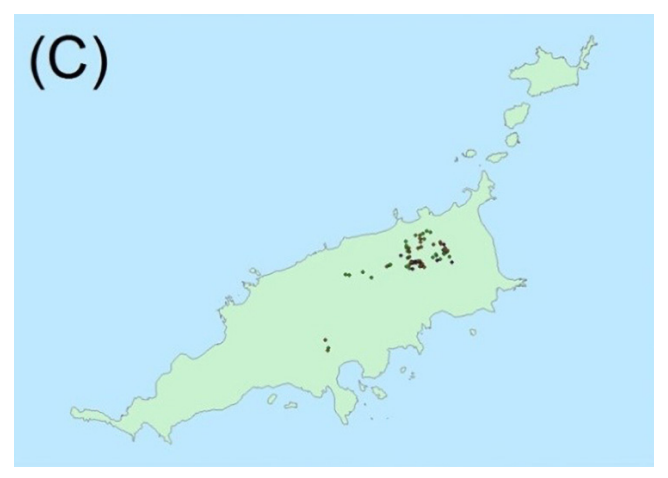

Figura 4 - Espacialização das pousadas em Fernando de Noronha (1988-1995)

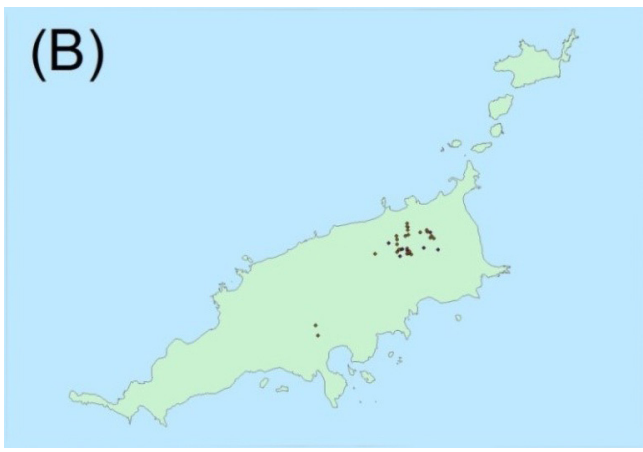

Figura 6 - Espacialização das pousadas em Fernando de Noronha (2011-2016)

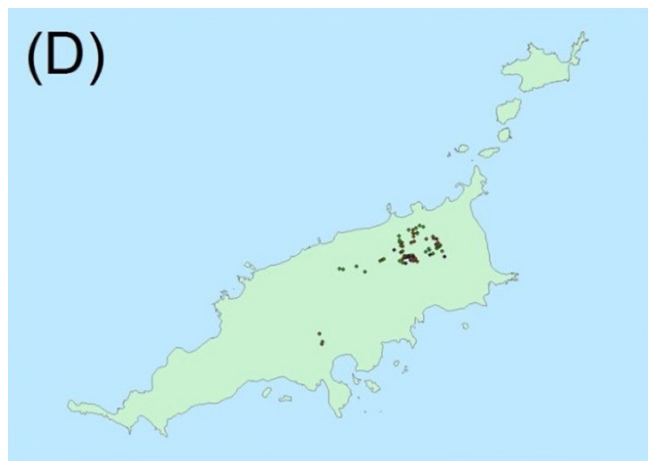

Fonte - Elaborado pelos autores com base em ADEFN/DHT (2014) e em pesquisa direta

Figura 7 - Evolução do fluxo turístico por via aérea (1995-2015)

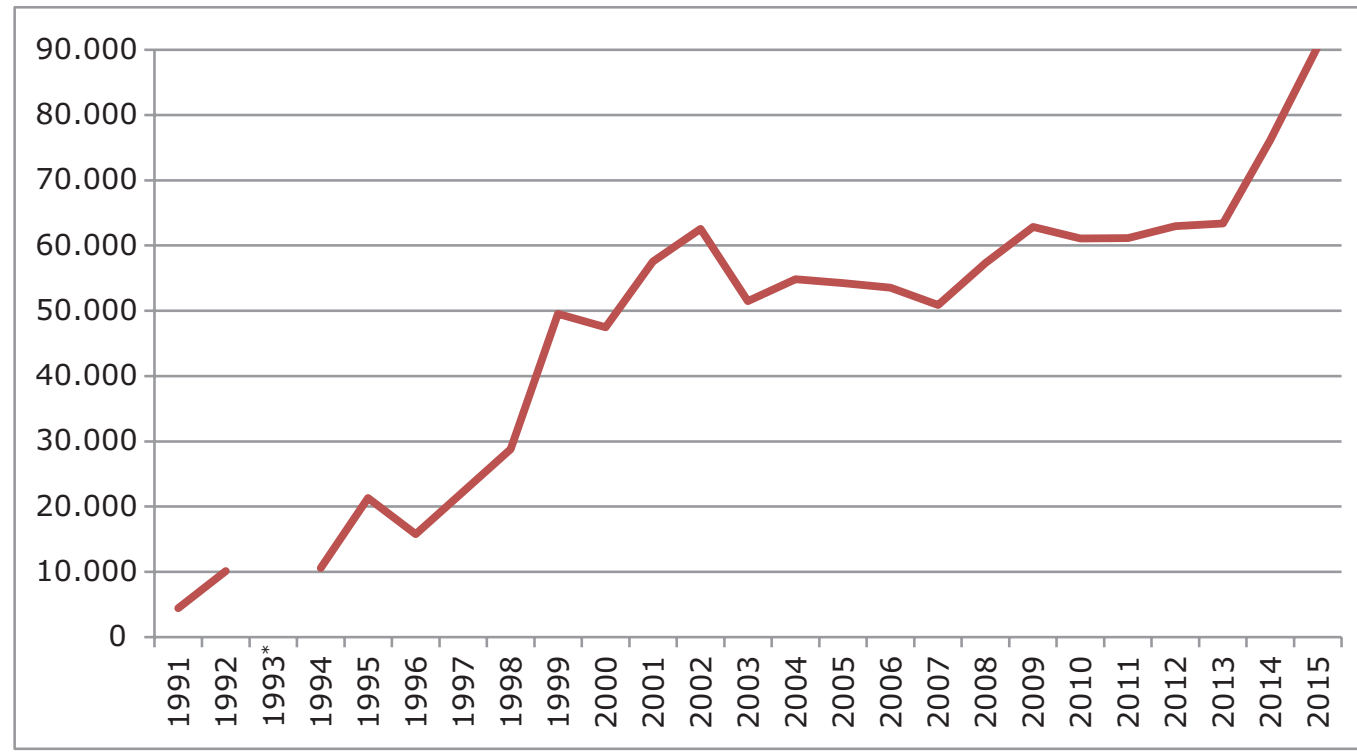

*Informação inexistente

Fonte - Cordeiro (2016) 
Na última década, muitos empresários externos passaram a investir em residências dos ilhéus ou em pequenas pousadas domiciliares para transformá-las em verdadeiros empreendimentos de luxo. Cada vez mais estabelecimentos simples e modestos (que na realidade nada mais eram do que as casas dos próprios ilhéus, adaptadas para receber visitantes) dão lugar a pousadas caras e sofisticadas. A arquitetura (cuidadosamente) rústica dessas novas pousadas não muda o fato de que o público interessado em nelas se hospedar precisa pagar, por exemplo, mais de $\mathrm{R} \$ 2.200,00$ em uma diária e mais de $\mathrm{R}$ \$ 100,00 em uma refeição.

Esse processo não se verifica apenas entre as pousadas. Os pequenos restaurantes também estão cedendo lugar a estabelecimentos cada vez mais sofisticados. 0 concorrido (e caro) Réveillon da Pousada Zé Maria, repleto de celebridades, é outro exemplo do nível de sofisticação que a ilha vem experimentando. Ou seja, o que se verifica em Fernando de Noronha é a consolidação de um destino que progressivamente vai se tornando um enclave de exceção, reservado a poucos endinheirados. Eis, pois, a situação atual da turistificação de Fernando de Noronha: a retomada da condição de destino de luxo, dessa vez não na esteira da atuação do Estado (seja militar ou civil), mas sim da iniciativa privada. Tal constatação traz a reboque uma reflexão incontornável: qual a consequência desse modelo de turistificação para a comunidade local?

Segundo alguns ilhéus entrevistados, a turistificação da ilha sob a ótica do luxo desencadeou uma alta nos preços dos produtos e, por conseguinte, o aumento do custo de vida, a tal ponto que a permanência na localidade se tornou difícil. Com feito, a alta do custo de vida motivada pelo turismo não é nenhuma novidade (Almeida, 1999; Fonteles, 2004; Krippendorf, 2003; Ouriques, 2005). Ao ser cobiçado por visitantes, é natural que em determinado destino o custo dos produtos e serviços se eleve. Esse aumento é experimentado pelos turistas, mas também pela comunidade local. Em se tratando de um ambiente insular, onde o custo de vida já não costuma ser baixo, a situação torna-se ainda mais dramática porque as opções para contornar os aumentos são praticamente inexistentes.

Há também a ação dos investidores externos que oferecem valores generosos pelas simples casas dos ilhéus, no afã de transformá-las em pousadas (mesmo sem terem obtido a autorização formal da ADEFN para funcionamento), justamente para aproveitar um nicho de mercado em ascensão. De acordo com os próprios ilhéus, é cada vez mais comum quem opte por arrendar sua casa a um empresário, geralmente por $\mathrm{R} \$ 5.000,00$ mensais (em alguns casos esse valor pode chegar a $\mathrm{R} \$ 10.000,00)$, para viver dessa renda no continente ou mesmo no exterior. Como nota Cleto (2013, p. 127): "arrendar a casa virou um plano de carreira, acima da ligação com a terra e a identidade noronhense".

Tal situação não tem a ver meramente com a comodidade de ter uma renda fixa para viver no continente. Trata-se também de uma questão de mercado: como ilhéus proprietários de pequenas pousadas conseguiriam competir com pousadas cujos donos são investidores externos dotados de capital financeiro? Conforme alguns entrevistados, a maior parte dos ilhéus não consegue arcar com investimentos próprios em seus estabelecimentos porque, sendo o arquipélago patrimônio da União, todos os imóveis e terrenos também o são, o que impede os moradores de utilizá-los como garantia fiduciária, hipotecária ou creditícia exigida por instituições de crédito. Também alegam não possuir incentivos do governo estadual para contornar esse problema. Desprovidos de capital, os pequenos 
proprietários de pousadas não conseguem investir em nelas de modo a torná-las competitivas perante as pousadas que contam com investimentos externos. Para muitos pequenos proprietários, então, a saída encontrada tem sido arrendar seus estabelecimentos ou residências.

A combinação do aumento do custo de vida com o assédio do investidor externo tem ocasionado, segundo se apurou, um processo de "êxodo insular". Convém chamar a atenção para as consequências desse processo: quando a comunidade local migra, há um enfraquecimento do tecido social; as relações sociais esmaecem-se porque a comunidade que animava o destino, que dava vida a ele, fragmenta-se e tende ao desaparecimento. Tem-se, assim, um processo de turistificação que, ao invés de contribuir para desenvolver o destino e melhorar a qualidade de vida da comunidade local, acaba por produzir um espaço vazio de sentido, cujo elemento animador é o turista - um sujeito que, a bem da verdade, é apenas um passante e não tem compromisso com o lugar. Nessas circunstâncias, cria-se um espaço no qual as relações entre os indivíduos são impessoais e destituídas de referências comuns a um grupo. Em outras palavras: produz-se um espaço sem identidade (artificial), um pastiche.

\section{Considerações finais}

O turismo não é uma atividade inocente ou despropositada, mas uma invenção humana que atende aos interesses do modelo econômico vigente e, portanto, é cheia de intenções, propósitos e ideologias (Coriolano, 2006). Logo, restringir os efeitos da turistificação meramente à inserção de infraestruturas (sobretudo hoteleiras) nos espaços é ignorar que a atividade pode inserir, eliminar e alterar objetos nesses territórios (meios de hospedagem, restaurantes, equipamentos de lazer etc.), ou mesmo remodelar as funções desses objetos, modificando seus significados. É ignorar, igualmente, que na conformação dos espaços tiveram lugar diferentes interesses e, portanto, que o turismo impõe uma lógica própria de utilização do território, produzindo diversas modificações nas estruturas locais e, por conseguinte, na sociedade (Körössy, 2008).

Por essa razão é imperativo não aceitar o dado como algo pronto, muito menos natural. É preciso avançar para além do óbvio e estudar a ação da sociedade sobre o espaço, que produz e reproduz formas visíveis ao observador, mas que necessitam ser investigadas na sua essência (Andrade, 2008). É preciso, como diz Eagleton (1986 apud Soja, 1993, p. 20), "virar pelo avesso a tapeçaria imponente, para expor em todo o seu confuso emaranhamento, desprovido de qualquer glamour, os fios que compõem a próspera imagem que ela expõe ao mundo".

A partir dessa perspectiva, o artigo se propôs a analisar o processo de turistificação de Fernando de Noronha, ocorrido, como se constatou, em dois momentos. 0 primeiro, entre as décadas de 1960/1970, foi marcado pela utilização das infraestruturas que os militares norte-americanos deixaram, adaptadas para fins turísticos, especificamente hospedagem. No decurso desses primeiros anos, a atividade praticamente nada significava para Fernando de Noronha. A infraestrutura turística resumia-se à Pousada Esmeralda, que, por sua vez, nada mais era do que um conjunto de quartos adaptados para atender às necessidades de uma demanda incipiente e sem muitas exigências. 
O segundo momento se dá ao longo das décadas de 1970 e 1980, primeiramente no governo militar e depois no civil, com a emergência de uma rationale para o espaço insular: convertê-lo em um destino de luxo. Essa lógica, no entanto, cai por terra quando a gestão do arquipélago passa ao controle do governo estadual de Pernambuco na década de 1990. A partir daí abandona-se a ideia de um enclave de luxo e privilegia-se, ao contrário, sua popularização, uma vez que o turismo passou a ser entendido como a alternativa por excelência para o desenvolvimento econômico local. Esse é o momento em que o turismo efetivamente começa a ser praticado em Fernando de Noronha.

Da análise desse transcurso percebe-se que, de uma forma ou de outra, a turistificação de Fernando de Noronha sempre esteve voltada para a constituição de um destino de luxo. Fosse com os militares (com seus planos para campos de golfe e área para hipismo), fosse com a administração civil de Fernando Mesquita (com seu hotel de quatro estrelas e 100 unidades habitacionais na Praia da Conceição), a ideia sempre foi desenvolver um enclave de exceção. Hodiernamente essa tendência se mantém. A diferença é que, se antes essa tarefa foi capitaneada pelo Estado, a partir da reanexação a iniciativa privada assumiu o protagonismo.

Não deixa de ser curioso notar que, se antes o luxo constituía o objetivo declarado do Estado para a turistificação do espaço insular (ainda que isso não tenha se concretizado), hoje é a omissão do Estado que a viabiliza. A partir da perspectiva lefebvriana, que entende o processo de produção do espaço como permeado de intencionalidade, é possível levantar a suspeita de que a omissão do poder público tem mais a ver com a estratégia de elitização do espaço do que com uma eventual insuficiência do aparelho estatal para fiscalizar e coibir a atuação dos agentes privados. Por vezes não fazer nada é até mais eficaz do que fazer algo. Se de fato o poder público ainda tem intenção de converter Fernando de Noronha em um destino de luxo, a opção mais simples parece ser a sua inação.

\section{REFERÊNCIAS}

Administração do Distrito Estadual de Fernando de Noronha/Departamento de Hotelaria e Turismo - ADEFN/DHT (2014). Diagnóstico da situação atual dos meios de hospedagem do arquipélago de Fernando de Noronha. Recife, PE: UFPE/PROEXT/DHT.

Almeida, M. (1999). Cultura: invenção e construção do objeto turístico. Espaço aberto turismo e formação profissional. Fortaleza, CE: AGB-Seção Fortaleza.

Andrade, M. C. (2008). Geografia: ciência da sociedade. Recife, PE: Editora Universitária da UFPE.

Barros, N. (1998). Manual de Geografia do Turismo: meio ambiente, cultura e paisagens. Recife, PE: Editora Universitária de UFPE.

Belhassen, Y., Uriely, N. \& Assor, O. (2007). The touristification of a conflict zone: the case of Bil'in. Annals of Tourism Research, 49, 174-189.

Brasil. (1938). Decreto-Lei no 640, de 22 de agosto de 1938. Diário Oficial [da] República Federativa do Brasil, Brasília, DF, p. 16975.

Brasil. (1987). Lei no 7.608, de 30 de junho de 1987. Diário Oficial [da] República Federativa do Brasil, Brasília, DF, p. 10293. 
Briguglio, L. (1995). Small island developing states and their economic vulnerabilities. World Development, 23(9), 1615-1632.

Briguglio, L. \& Briguglio, M. (1996). Sustainable tourism in the Maltese Islands. In L. Briguglio, R. Butler \& W. Leal Filho (Eds.). Sustainable tourism in islands \& small states: case studies (pp. 162-179). London: Pinter.

Carlos, A. F. (2012). Da "organização" à "produção" do espaço no movimento do pensamento geográfico. In A. F. Carlos, M. L. Souza \& M. Sposito. A produção do espaço urbano: agentes e processos, escalas e desafios (pp. 53-73). São Paulo, DF: Contexto.

Cleto, A. (2013). De cemitério de ideias a embrião de sementes: uma experiência sobre a mobilização social em Fernando de Noronha. Dissertação de Mestrado, Universidade de Brasília, Brasília, DF. Recuperado de https://goo.gl/YhEjMv

Cordeiro, I. (2016). O turismo no processo de (re)produção de espaços insulares pela acumulação por despossessão - Fernando de Noronha (Pernambuco). Tese de Doutorado, Universidade Federal de Pernambuco, Recife, PE. Recuperado de https://goo.gl/zvwsTS

Cordeiro, I. \& Gomes, E. (2016). A dinâmica da produção do espaço pelo turismo em Fernando de Noronha (Pernambuco/Brasil) e suas consequências. TURyDES - Revista de Investigación en Turismo y desarrollo local, 9, 1-16.

Cordeiro, I. \& Gomes, E. (2017). A produção do espaço turístico via acumulação por despossessão: o caso de Fernando de Noronha (Pernambuco). TURyDES - Revista de Investigación en Turismo y desarrollo local, 22, 1-20.

Coriolano, L. N. (2006). O turismo nos discursos, nas políticas e no combate à pobreza. São Paulo, SP: Annablume.

Cruz, R. (2007). Geografias do turismo: de lugares a pseudo-lugares. São Paulo, SP: Roca.

Fonseca, M. A. \& Costa, A. A. (2004). A racionalidade da urbanização turística em áreas deprimidas: o espaço produzido para o visitante. Mercator - Revista de Geografia da UFC, $3(6), 25-32$.

Fonteles, J. O. (2004). Turismo e impactos socioambientais. São Paulo, SP: Aleph.

Fratucci, A. (2007). Os processos de turistificação do espaço e atuação dos seus agentes produtores. In Anais do X Encontro Nacional de Turismo com Base Local, 2007, João Pessoa, PB. João Pessoa: UFPB.

Gonçalves, R. (2009). O Termo de Ajustamento de Conduta como instrumento mediador de conflitos de competências administrativas ambientais: o caso de Fernando de Noronha. Dissertação de Mestrado, Universidade Federal de Pernambuco, Recife, PE. Recuperado de https://goo.gl/LQXhMd

Instituto Brasileiro de Meio Ambiente e Recursos Naturais Renováveis - Ibama (1990). Plano de manejo Parque Nacional Marinho de Fernando de Noronha. Brasília, DF: Ibama.

Instituto Brasileiro do Meio Ambiente e dos Recursos Naturais Renováveis - Ibama (2005). Plano de Manejo - Fase 1 da Área de Proteção Ambiental APA Fernando de Noronha, Atol das Rocas e São Pedro e São Paulo. Encarte 3: Análise da Unidade de Conservação. Brasília, DF: Ibama.

Issa, Y. \& Dencker, A. (2006). Processos de turistificação: dinâmicas de inclusão e exclusão de comunidades locais. In Anais do IV SeminTUR - Seminário de Pesquisa em Turismo do Mercosul, 2006. Caxias do Sul, RS. Caxias do Sul: UCS.

Jornal do Brasil (1988). Agora sai. Caderno B, p. 3. 14.04.1988.

Jornal do Brasil (1988). Aviso de licitação: hotel 4 estrelas em Fernando de Noronha. 1으 Caderno, p. 9. 15.04.1988. 
Jornal do Brasil (1988). F. de Noronha divulga plano de zoneamento. 1ํㅡㄹ Caderno, p. 5. 17.05.1988.

Jornal do Commércio (1988). Arquipélago ainda não terá plano turístico. Nacional, p. 7. 13.12.1988.

Knafou, R. (1996). Turismo e Território: por uma abordagem científica do turismo. In A. Rodrigues. (Org.). Turismo e Geografia: reflexões teóricas e enfoques regionais (pp. 62-74). São Paulo: Hucitec.

Kokkranikal, J.; Mclellan, R. \& Baum, T. (2003). Island tourism and sustainability: A case study of the Lakshadweep Islands. Journal of Sustainable Tourism, 11(5), 426-447.

Körössy, N. (2008). Turismo e território: um estudo sobre a turistificação de Portimão (Algarve/Portugal) a partir da geografia do turismo. Dissertação de Mestrado, Universidade de Lisboa, Lisboa.

Krippendorf, J. (2003). Sociologia do turismo. Para uma nova compreensão do lazer e das viagens. São Paulo, SP: Aleph.

Lefebvre, H. (2013). La producción del espacio. Madrid: Capitán Swing.

Lins e Silva, M. (2013). Fernando de Noronha: cinco de séculos de história. Recife, PE: Editora Universitária da UFPE.

López, A. (2002). Análisis territorial de los flujos turísticos en el Corredor Los Cabos, Baja California Sur. Investigaciones Geográficas, 47, 131-149. Recuperado de https://goo.gl/ WvBvMU

Loureiro, F. \& Souza, A. (2003). A urbanização de espaços públicos como incentivo ao turismo sustentável: uma proposta para o Parque do Areal em Viana - MA. In L. N. Coriolano \& C. L. Lima. (Orgs.). Turismo comunitário e responsabilidade sócio-ambiental (pp. 197-210). Fortaleza, CE: Eduece.

Mesquita, D. (2012). O livro de Fernando de Noronha: a ilha contada por quem a escreve. São Paulo: Fundação Perseu Abramo.

Nascimento, G. R. (2009). Fernando de Noronha e os ventos da guerra fria (a relação entre Brasil e Estados Unidos nos anos de JK). Dissertação de Mestrado, Universidade Federal de Pernambuco, Recife, PE. Recuperado de https://goo.gl/EvTFbY

Nicolas, D. (1996). Elementos para un analisis sociogeografico del turismo. In A. Rodrigues. (Org.). Turismo e Geografia: reflexões teóricas e enfoques regionais (pp. 39-53). São Paulo, SP: Hucitec.

Ouriques, H. (2005). A produção do turismo: fetichismo e dependência. Campinas, SP: Alínea.

Pernambuco (1989). Lei no 10.403, de 29 de dezembro de 1989. Diário Oficial do Estado de Pernambuco, Recife, p. 5-7.

Pessoa, G. T. (2014). Fernando de Noronha: uma ilha-presídio nos trópicos (1833-1894). Cadernos Mapa, 10. Rio de Janeiro: Arquivo Nacional. Recuperado de https://goo.gl/Q8UDvt

Rocha Lima, J. C. (2000). Nas águas do Arquipélago de Fernando de Noronha. Tese de Doutorado, Pontifícia Universidade Católica de São Paulo, São Paulo, SP.

Rozowykwiat, T. (2006). Arraes. São Paulo: Iluminuras.

Soja, E. W. (1993). Geografias pós-modernas: a reafirmação do espaço na teoria social crítica. Rio de Janeiro: Zahar.

Sousa, A. (1994). El ocio turístico en las sociedades industriales avanzadas. Barcelona: Bosch. United Nations World Tourism Organization - UNWTO (2004). Making tourism work for small island developing states. Madrid: World Tourism Organization. 
United Nations World Tourism Organization - UNWTO (2016). UNWTO Tourism Highlights: 2016 Edition. Madrid: World Tourism Organization. Recuperado de https://goo.gl/BjveS5

Urry, J. (1996). O olhar do turista: lazer e viagens nas sociedades contemporâneas. São Paulo, SP: Studio Nobel.

Recebido em: $21 / 04 / 2017$

Aprovado em: 23/03/2018

\section{CONTRIBUIÇÕES}

Itamar José Dias e Cordeiro: Definição do problema de pesquisa e objetivos. Desenvolvimento da proposição teórica. Realização da revisão bibliográfica e fundamentação teórica. Escolha dos procedimentos metodológicos. Coleta de dados. Análise de dados. Elaboração de tabelas, gráficos e figuras. Revisão crítica do manuscrito. Redação do manuscrito. Adequação do manuscrito às normas da RTA.

Nathália Körössy Leite: Definição do problema de pesquisa e objetivos. Desenvolvimento da proposição teórica. Realização da revisão bibliográfica e fundamentação teórica. Revisão crítica do manuscrito. Redação do manuscrito.

Edvânia Tôrres Aguiar Gomes: Revisão crítica do manuscrito. Redação do manuscrito. 